\title{
Severe Pulmonary Adverse Effects in Lymphoma Patients Treated with Cyclophosphamide, Doxorubicin, Vincristine, and Prednisone (CHOP) Regimen Plus Rituximab
}

\author{
Kyu-Hyoung Lim', Ho-II Yoon², Young Ae Kang'2, Keun-Wook Lee², Jee Hyun Kim², Soo-Mee Bang², Jae Ho Lee², \\ Choon-Taek Lee ${ }^{1,2}$, and Jong Seok Lee ${ }^{1,2}$
}

${ }^{1}$ Department of Internal Medicine, Seoul National University College of Medicine, Seoul; ${ }^{2}$ Department of Internal Medicine, Seoul National University Bundang Hospital, Seongnam, Korea

Background/Aims: The aim of our study was to determine the incidence and clinical features of severe pulmonary complications in patients receiving cyclophosphamide, doxorubicin, vincristine, and prednisone (CHOP) or rituximab plus CHOP (R-CHOP) as the initial treatment for lymphoma.

Methods: A retrospective analysis of pulmonary infection and drug-induced interstitial pneumonitis (DIIP) was performed using lymphoma registry data. R-CHOP was administered in 71 patients and CHOP in 29 patients.

Results: The severe pulmonary adverse events tended to occur more frequently with R-CHOP $(18.3 \%)$ than CHOP alone $(13.8 \%)$, although the difference was not significant $(p=0.771)$. DIIP occurred in five patients in the R-CHOP arm (7\%) and in one in the CHOP arm (3\%). The continuous use of steroids for conditions other than lymphoma significantly increased the risk of pulmonary infection including Pneumocystis jiroveci pneumonia $(p=$ 0.036 ) in the multivariate analysis. International prognostic index, tumor stage, smoking, previous tuberculosis, chronic obstructive pulmonary disease, and lymphoma involvement of lung parenchyma were not related to pulmonary adverse events. Patients who experienced severe pulmonary events showed shorter survival when compared to those without complications $(p=0.002)$.

Conclusions: Our experiences with serial cases with DIIP during chemotherapy and the correlation of continuous steroid use with pulmonary infection suggest that the incidence of pulmonary complications might be high during lymphoma treatment, and careful monitoring should be performed. (Korean J Intern Med 2010;25:86-92)

Keywords: Rituximab; Drug therapy; Lymphoma, non-Hodgkin; Adverse effects; Lung diseases, interstitial

\section{INTRODUCTION}

Rituximab is a chimeric monoclonal antibody that was approved for the treatment of low-grade or follicular, relapsed, or refractory lymphoma and CD2O positive Bcell non-Hodgkin's lymphoma (NHL). It is now considered as a part of the standard therapy for CD2O positive B-cell NHL, especially for diffuse large B-cell lymphoma [1]. Over 540,000 patients worldwide have now received rituximab and serious adverse reactions have occurred only in a minority of patients; in the vast majority, rituximab is safe and well tolerated [2]. The most common adverse events were infusion-related and included fever, chills, and rigors. Respiratory complications could include cough, rhinitis, brochospasm, dyspnea, and sinusitis [3]. Severe pulmonary complications such as cryptogenic organizing pneumonia and druginduced interstitial pneumonitis (DIIP) are very rare, with most of our knowledge coming from case reports [4-6].

However, we have experienced cases of rituximab- 
Table 1. Baseline characteristics of patients treated with CHOP or R-CHOP

\begin{tabular}{|c|c|c|c|}
\hline Variables & $\begin{array}{c}\text { CHOP } \\
(n=29)\end{array}$ & $\begin{array}{c}\mathrm{R}-\mathrm{CHOP} \\
(\mathrm{n}=71)\end{array}$ & $p$ value \\
\hline Age, yr & $61.7(19.7-80.7)$ & $61.4(21-83.8)$ & NS \\
\hline Sex & & & NS \\
\hline Male & $17(56.6)$ & $38(53.5)$ & \\
\hline Female & $12(41.4)$ & $33(45.5)$ & \\
\hline Histology according to WHO & & & 0.000 \\
\hline B cell & $5(17.3)$ & $71(100)$ & \\
\hline T cell & $24(82.7)$ & $0(0)$ & \\
\hline Age-adjusted IPI & & & NS \\
\hline Low & $9(31.0)$ & $23(32.4)$ & \\
\hline Low-intermediate & $9(31.0)$ & $16(22.5)$ & \\
\hline High-intermediate & $7(24.1)$ & $22(31.0)$ & \\
\hline High & $4(13.8)$ & $10(14.1)$ & \\
\hline Performance status & & & NS \\
\hline $0-1$ & $19(65.5)$ & $58(81.7)$ & \\
\hline $2-4$ & $10(34.5)$ & $13(18.3)$ & \\
\hline Stage & & & NS \\
\hline 1 & $7(24.1)$ & $5(7.0)$ & \\
\hline$\|$ & $12(41.4)$ & $30(42.3)$ & \\
\hline III & $5(17.2)$ & $11(15.5)$ & \\
\hline IV & $5(17.2)$ & $25(35.2)$ & \\
\hline Steroid long term use & & & NS \\
\hline Yes & $2(6.9)$ & $4(5.6)$ & \\
\hline No & 27 (93.1) & $67(94.4)$ & \\
\hline Lung parenchymal involvement & $4(13.8)$ & $5(7.0)$ & NS \\
\hline Bone marrow involvement & $1(3.4)$ & $11(15.5)$ & NS \\
\hline Smoking & $8(27.6)$ & $14(19.2)$ & NS \\
\hline History of pulmonary tuberculosis & $2(6.9)$ & $7(9.9)$ & NS \\
\hline Chronic obstructive pulmoanry disease & $2(6.9)$ & $3(4.2)$ & NS \\
\hline Chemotherapy cycles & $5(1-6)$ & $5(1-8)$ & NS \\
\hline
\end{tabular}

Values are presented as median (range) or number (\%) unless otherwise indicated.

CHOP, cyclophosphamide, doxorubicin, vincristine, and prednisone; R-CHOP, rituximab plus CHOP; NS, not significant; WHO, World Health Organization; IPI, international prognostic index.

associated pulmonary adverse events very frequently. Therefore, this study analyzed these adverse events and the clinical features of patients treated with cyclophosphamide, doxorubicin, vincristine, and prednisone (CHOP) or rituximab plus $\mathrm{CHOP}$ (R-CHOP).

\section{METHODS}

\section{Eligibility of patients}

We retrospectively reviewed patients with NHL diagnosed between September 2003 and April 2007. Eligible patients were treated with R-CHOP or CHOP as the first induction therapy for lymphoma at Seoul National University Bundang Hospital. Patients with acquired immunodeficiency syndrome- or central nervous systemassociated lymphoma were excluded.

\section{Treatment}

Patients treated with $\mathrm{CHOP}$ received the combination of cyclophosphamide (750 mg/m², day 1), doxorubicin (50 $\mathrm{mg} / \mathrm{m}^{2}$, day 1$)$, vincristine $\left(1.4 \mathrm{mg} / \mathrm{m}^{2}\right.$, up to a maximal dose of $2 \mathrm{mg}$, day 1), and prednisone ( $40 \mathrm{mg} / \mathrm{m}^{2} /$ day, days 1 to 5 ). They were treated every 3 weeks. Patients treated with R-CHOP received rituximab $\left(375 \mathrm{mg} / \mathrm{m}^{2}\right)$ on day 1 of each cycle of $\mathrm{CHOP}$ according to standard prescribing 
guidelines, following the administration of oral acetaminophen (650 mg) and intravenous pheniramine (45.5 $\mathrm{mg}$ ). An additional two cycles of CHOP or RCHOP were given after achievement of complete remission.

\section{Assessment of pulmonary adverse events}

An adverse event was defined as any adverse change from the patient's baseline condition. Each event was graded according to the National Cancer Institute Common Toxicity Criteria grading system. The definition of severe pulmonary complications was all adverse events of grade 3 or more that occurred in the lungs, such as infection and DIIP, after chemotherapy was completed. The diagnosis of pulmonary complications, especially DIIP, was made mainly by radiological findings and laboratory or pathological methods along with clinicians' experience. Diagnostic criteria were as follows. The radiological method consisted mainly of high-resolution computed tomography (HRCT). HRCT findings in DIIP showed a diffuse interstitial pattern, such as ground-glass opacity, alveolitis, and diffuse infiltrates. The predominant abnormalities on pulmonary function tests were a restrictive pattern and a reduction in the diffusing capacity of the lung for carbon monoxide (DLCO). Pathological results were consistent with interstitial fibrosis. Clinical aspects included symptoms, no evidence of infectious etiology, association with drug administration, and good response to immunosuppressants such as corticosteroids.

\section{Statistical methods}

All continuous variables were analyzed using the MannWhitney $U$ test. Proportions were compared using the $\chi^{2}$ test or logistic regression analysis. Overall survival was estimated with the Kaplan-Meier method and was compared using the log-rank test. Statistical analysis was
Table 2. Histologic subtypes of non-Hodgkin's lymphoma by chemotherapy regimens

\begin{tabular}{lcc}
\hline Histolgy & $\begin{array}{c}\text { CHOP } \\
(\mathrm{n}=29)\end{array}$ & $\begin{array}{c}\mathrm{R}-\mathrm{CHOP} \\
(\mathrm{n}=71)\end{array}$ \\
\hline Diffuse large B cell lymphoma & 10 & 65 \\
Anaplastic large cell lymphoma & 6 & 0 \\
Extranodal NK/T cell lymphoma & 2 & 0 \\
Angioimmunoblastic T cell lymphoma & 3 & 0 \\
Blastic NK cell lymphoma & 1 & 0 \\
Extranodal marginal zone B cell lymphoma & 1 & 0 \\
Peripheral T cell lymphoma & 3 & 0 \\
Small lymphocytic lymphoma & 1 & 0 \\
T cell lymphoblastic lymphoma & 1 & 0 \\
Nasal NK/T cell lymphoma & 1 & 0 \\
Follicular lymphoma & 0 & 3 \\
B cell lymphoma & 0 & 1 \\
Mantle cell lymphoma & 0 & 1 \\
Mature B cell lymphoma & 0 & 1 \\
\hline
\end{tabular}

CHOP, cyclophosphamide, doxorubicin, vincristine, and prednisone; $\mathrm{R}-\mathrm{CHOP}$, rituximab plus $\mathrm{CHOP}$.

performed with SPSS version 10.0 (SPSS Inc., Chicago, IL, USA) and significance levels were two-sided at $p<0.05$.

\section{RESULTS}

\section{Patient characteristics}

The subjects consisted of 100 patients: 71 treated with R-CHOP and 29 with CHOP as an initial regimen, all of whom received at least one cycle of chemotherapy. The median age of the patients was 61 years (range, 19 to 83). No significant difference existed in any clinical characteristics between the two groups, except for histology (Table 1). Most patients treated with CHOP had NHL of T-cell

Table 3. Pulmonary complications in patients treated with CHOP or R-CHOP

\begin{tabular}{lccc}
\hline Pulmonary complications & $\begin{array}{c}\text { CHOP } \\
(\mathrm{n}=29)\end{array}$ & $\begin{array}{c}\text { R-CHOP } \\
(\mathrm{n}=71)\end{array}$ & $p$ value \\
\hline Pneumocystis jirovecii pneumonia & $4^{\mathrm{a}}$ & 2 & $\mathrm{NS}$ \\
Drug-induced interstitial pneumonitis & 1 & 5 & $\mathrm{NS}$ \\
Bacterial pneumonia with neutroepnia & 0 & 5 & $\mathrm{NS}$ \\
Tuberculosis & 0 & 1 & NS \\
Total $(\%)$ & $4^{\mathrm{b}}(13.8)$ & $13(18.3)$ & NS \\
\hline
\end{tabular}

$\mathrm{CHOP}$, cyclophosphamide, doxorubicin, vincristine, and prednisone; R-CHOP, rituximab plus $\mathrm{CHOP}$; NS, not significant.

a Drug-induced interstitial pneumonitis led to prolonged steroid usage, which resulted in Pneumocystis jirovecii pneumonia with positive direct fluorescent monoclonal antibody assay later.

${ }^{b}$ One patient suffered from both drug-induced interstitial pneumonitis and Pneumocystis jirovecii pneumonia. 


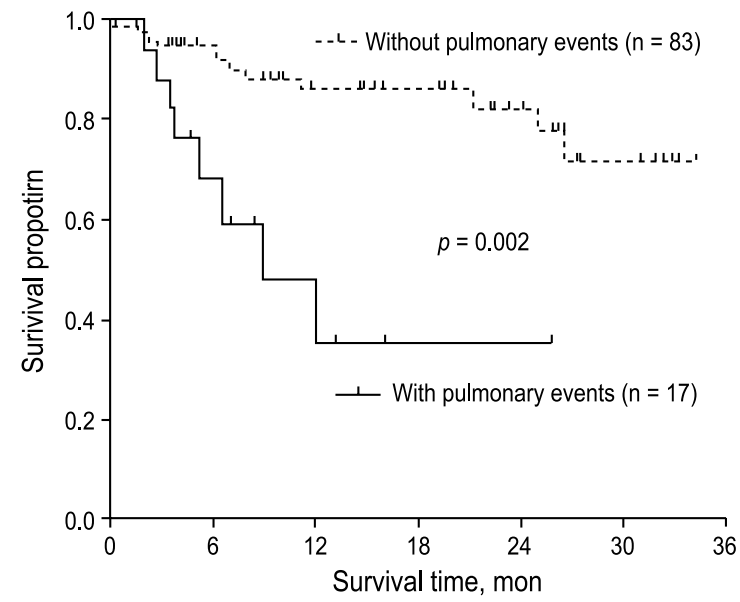

Figure 1. Comparison of survival between patients with or without pulmonary adverse events.

lineage (82.7\%), while all patients treated with R-CHOP had NHL of B-cell lineage (Table 2). None received Pneumocystis jirovecii pneumonia (PJP) prophylaxis or prophylactic antibiotics during chemotherapy.

\section{Clinical features of pulmonary adverse events}

Pulmonary complications in patients receiving treatment with CHOP or R-CHOP are listed in Table 3. Pulmonary complications were seen in 13 cases (18.3\%) in the R-
CHOP group and four (13.8\%) in the CHOP group. Median age in the CHOP and R-CHOP group was 61.7 and 61.4 years, respectively. The most frequent pulmonary complications in the R-CHOP group were DIIP $(7.0 \%, n=$ 5) and bacterial pneumonia associated with neutropenic fever $(6.8 \%, \mathrm{n}=5)$. The former was diagnosed by pathological confirmation $(n=1)$ or combination of HRCT and consultation with a pulmonologist $(\mathrm{n}=4)$. Clinical features of patients with rituximab-induced interstitial pneumonitis (RIIP) are summarized in Table 4. PJP $(2.8 \%, \mathrm{n}=2)$ was diagnosed by positive direct fluorescentantibody (DFA) assay from bronchoalveolar lavage. One patient without a previous history of pulmonary tuberculosis (TB) developed TB after three cycles of RCHOP. The median time from the start of R-CHOP to DIIP was 2.9 months (range, 0.9 to 3.9).

Four patients treated with CHOP developed PJP, three of whom were negative with DFA. However, we diagnosed three patients with PJP after considering all the factors, such as exclusion of bacterial or fungal pneumonia, CT imaging, and improvement after administration of trimethoprim-sulfamethoxazole. In one patient who was positive by DFA, PJP appeared secondary to prolonged steroid use after he was diagnosed with DIIP.

Table 4. Clinical features of patients with rituximab-induced interstitial pneumonitis

\begin{tabular}{|c|c|c|c|c|c|c|c|c|c|c|c|}
\hline & $\begin{array}{l}\text { Age, } \\
\text { yr }\end{array}$ & Sex & $\begin{array}{l}\text { Subtype } \\
\text { of lymphoma }\end{array}$ & $\begin{array}{c}\text { Cycle, } \\
\text { n }\end{array}$ & $\begin{array}{l}\text { Time from } \\
\text { rituximab } \\
\text { administration } \\
\text { to DIIP, day }\end{array}$ & $\begin{array}{l}\text { Presenting } \\
\text { symptom }\end{array}$ & CT finding & DLCO & Pathology & Treatment & Outcome \\
\hline Case 1 & 65 & Male & DLBL & 6 & 14 & Fever & $\begin{array}{l}\text { Ground-glass } \\
\text { opacity; } \\
\text { Interstitial thickening }\end{array}$ & NA & DIIP & Prednisone & Improved \\
\hline Case 2 & 64 & Male & DLBL & 1 & 29 & Dry cough & $\begin{array}{l}\text { Ground-glass } \\
\text { opacity; } \\
\text { Fibrotic and reticular } \\
\text { density }\end{array}$ & NA & NA & Prednisone & Expired \\
\hline Case 3 & 71 & Male & DLBL & 6 & 27 & Dyspnea & $\begin{array}{l}\text { Ground-glass } \\
\text { opacity; } \\
\text { Interstitial thickening }\end{array}$ & NA & DIIP & Prednisone & Improved \\
\hline Case 4 & 54 & Male & DLBL & 8 & 29 & Dyspnea & $\begin{array}{l}\text { Diffuse interstitial } \\
\text { thickening }\end{array}$ & Decrease & DIIP & Prednisone & Improved \\
\hline Case 5 & 86 & Female & DLBL & 3 & 22 & Dyspnea & $\begin{array}{l}\text { Diffuse ground-glass } \\
\text { opacity }\end{array}$ & NA & NA & Prednisone & Improved \\
\hline
\end{tabular}

CT, computed tomography; DLCO, diffusing capacity of the lung for carbon monoxide; DLBL, diffuse large B-cell lymphoma; DIIP, drug-induced interstitial pneumonitis; NA, not available. 
Table 5. Patient characteristics according to pulmonary adverse events

\begin{tabular}{|c|c|c|c|}
\hline Variables & $\begin{array}{l}\text { Pulmonary complications } \\
\qquad(\mathrm{n}=17)\end{array}$ & $\begin{array}{l}\text { No pulmonary complications } \\
\qquad(\mathrm{n}=83)\end{array}$ & $p$ value \\
\hline Age, yr & $62(46-84)$ & $59(20-79)$ & NS \\
\hline \multicolumn{4}{|l|}{ Sex } \\
\hline Male & $11(64.7)$ & $44(53.0)$ & \multirow[t]{2}{*}{ NS } \\
\hline Female & $6(35.3)$ & $39(47.0)$ & \\
\hline \multicolumn{4}{|l|}{ Age-adjusted IPIa } \\
\hline Low & $1(5.9)$ & $31(37.3)$ & \multirow{4}{*}{0.007} \\
\hline Low-intermediate & $4(23.5)$ & $21(25.3$ & \\
\hline High-intermediate & $8(47.1)$ & $21(25.3)$ & \\
\hline High & $4(23.5)$ & $10(12.0)$ & \\
\hline \multicolumn{4}{|l|}{ Performance status } \\
\hline $0-1$ & $13(76.5)$ & $64(77.1)$ & \multirow[t]{2}{*}{ NS } \\
\hline $2-4$ & $4(23.5)$ & $19(22.9)$ & \\
\hline \multicolumn{4}{|l|}{ Stage } \\
\hline I & $0(0)$ & $12(14.5)$ & \multirow{4}{*}{0.012} \\
\hline$\|$ & $4(23.5)$ & $38(45.8)$ & \\
\hline III & $6(35.3)$ & $10(12.0)$ & \\
\hline IV & $7(41.2)$ & $23(27.7)$ & \\
\hline \multicolumn{4}{|l|}{ Steroid long term use } \\
\hline Yes & $4(23.5)$ & $2(2.4)$ & \multirow[t]{2}{*}{0.007} \\
\hline No & $13(76.5)$ & $81(97.6)$ & \\
\hline Lung parenchymal involvement & $2(11.8)$ & $7(8.4)$ & NS \\
\hline Bone marrow involvement & $3(17.6)$ & $9(10.8)$ & NS \\
\hline Smoking & $5(29.4)$ & $17(20.5)$ & NS \\
\hline History of pulmonary tuberculosis & $1(5.9)$ & $8(9.6)$ & NS \\
\hline Chronic obstructive pulmoanry disease & $2(7.4)$ & $3(3.6)$ & NS \\
\hline Chemotherapy cycles & $5(1-7)$ & $6(1-8)$ & NS \\
\hline
\end{tabular}

Values are presented as median (range) or number (\%) unless otherwise indicated.

NS, not significant; IPI, international prognostic index.

${ }^{a}$ Age $>60$, serum lactate dehydrogenase concentration greater than normal, Eastern Cooperative Oncology Group (ECOG) performance status $\geq 2$, Ann Arbor clinical stage III or IV, number of involved extranodal disease sites $>1$.

\section{Clinical variables related to pulmonary complications}

Initial chemotherapy regimens such as CHOP and RCHOP did not differ significantly for incidence of pulmonary adverse events $(p=0.771)$. The patients' characteristics were compared according to the pulmonary complications, irrespective of chemotherapy regimen (Table 5). For univariate analysis, higher age-adjusted international prognostic index (IPI), higher stage, and longer steroid usage were related to occurrence of pulmonary complications. Performance status, smoking, previous TB, comorbidity with chronic obstructive pulmonary disease, and lung parenchymal involvement by lymphoma were not related to pulmonary adverse events. In the multivariate analysis, only the prolonged use of steroids significantly increased the risk of PJP and pulmonary infection $(p=0.036)$.

Patients with pulmonary toxicity showed significantly lower overall survival than those without complications ( $p$ $=0.002$, Fig. 1). Eight of 17 patients with pulmonary complications died. The causes of death were as follows: two with DIIP, one with PJP, one with pneumonia, and four from disease progression.

\section{DISCUSSION}

Rituximab is a human/mouse chimeric monoclonal antibody (IgG1) that reacts specifically with the CD20 antigen that is expressed on $>95 \%$ of normal and 
malignant B cells, and induces complement-mediated and antibody-dependent cellular cytotoxicity. In patients with relapsed, low-grade NHL, peripheral blood B-cell depletion occurs within 24 to 48 hours after the first infusion of rituximab. Recovery of B cells begins 6 to 9 months after completion of therapy, and normal levels are obtained after 9 to 12 months [7]. The prolonged period of rituximabinduced B-cell depletion might compromise the immune system. However, the Groupe d'Etude des Lymphomes de l'Adulte (GELA) group compared R-CHOP with CHOP alone in elderly patients with aggressive NHL, and found no major difference between the two arms in terms of toxicity or severe infection, with a significantly superior survival in the R-CHOP group [1]. Recently, rituximab has been used as a first-line agent in combination with $\mathrm{CHOP}$ for the treatment of CD2O positive B-cell NHL.

Although the use of rituximab has increased, the rate of possible drug-induced lung injury is currently $<0.03 \%$ in more than 540,000 patients treated worldwide [2]. However, we have observed post-chemotherapy pulmonary toxicity more frequently. Although R-CHOP did not induce significantly more pulmonary complications than CHOP, our study showed that rituximab-containing therapy tended to cause DIIP and bacterial pneumonia more frequently. The former probably was related to rituximab, which was previously reported to have a low incidence [8-13].

According to one report of 16 patients with RIIP, the average number of cycles of rituximab prior to presentation of RIIP was four, and the most common symptoms at presentation included dyspnea (81\%), fever (72\%), and cough (36\%) [11]. Evaluations should include pulse oximetry or blood gas analysis, HRCT of the chest to seek out diffuse interstitial infiltrates, and pulmonary function tests to look for a restrictive pattern and decreased DLCO. Bronchoscopy with bronchoalveolar lavage should be performed to rule out an infectious etiology, and biopsy can demonstrate alveolar damage and interstitial fibrosis.

The pathogenesis of RIIP is largely unknown. A potential explanation for RIIP may be the induction and release of cytotoxic substances. Rituximab acts by binding to $\mathrm{CD} 20$ positive B cells. Toxicity and efficacy are related to events after binding, which include B-cell signaling, complement activation, direct apoptosis, and antibodydependent cellular cytotoxicity [14]. Complement activation and cytokine secretion seem to be causative factors of the side effects associated with infusion reactions [15]. In particular, tumor necrosis factor (TNF)- $\alpha$ has been postulated as the main component in the pathogenesis of RIIP because of its proinflammatory effects by inducing chemokines, inflammatory mediators, and angiogenic factors [16]. Therapy of RIIP must include immediate discontinuation of rituximab and highdose corticosteroids, and any other clinically necessary supportive therapy such as anti-TNF- $\alpha$ therapy might be attempted in patients whose clinical condition worsens despite corticosteroids [11]. The duration of steroid therapy is usually 1 to 2 months. Patients who worsen despite corticosteroids can have a fatal outcome [17].

Several factors could account for the higher incidence of DIIP in our study than that reported previously. The first factor was the failure to recognize this complication by attributing the DIIP symptoms to infection or the underlying disease in previous studies. The second was the distribution to higher age-adjusted IPI and stage in the R-CHOP group, which was attributed to more frequent pulmonary complications, by univariate analysis. When used in combination with a variety of chemotherapeutic regimens, rituximab is known to cause a higher rate of neutropenia, which does not translate into a higher infection rate $[18,19]$. However, the frequent neutropenia caused by R-CHOP may increase the probability of infection and lead to higher incidence of bacterial pneumonia than with CHOP alone. Reactivation of pulmonary TB was probably associated with impairment of cellular immunity induced by rituximab and steroids, even if in our one case.

Overall survival was analyzed according to whether patients had pulmonary complications. Overall survival in patients with severe pulmonary toxicity was shorter than that in patients without, which caused death by pulmonary complications themselves and disease progression after an inevitable discontinuation of treatment.

In conclusion, the incidence of rituximab-related pulmonary complications may be higher than has been reported previously [2]. These adverse events, especially DIIP, lead to prolonged use of corticosteroids, which may increase the risk of infection such as PJP and TB. Rituximab-induced pulmonary toxicity should be recognized early and treated effectively because of its associated high mortality and morbidity. Also, a prolonged use of corticosteroids for conditions other than lymphoma requires caution. 


\section{Conflict of interest}

No potential conflict of interest relevant to this article was reported.

\section{REFERENCES}

1. Coiffier B, Lepage E, Briere J, et al. CHOP chemotherapy plus rituximab compared with $\mathrm{CHOP}$ alone in elderly patients with diffuse large-B-cell lymphoma. N Engl J Med 2002;346:235-242.

2. Kimby E. Tolerability and safety of rituximab (MabThera). Cancer Treat Rev 2005;31:456-473.

3. Bienvenu J, Chvetzoff R, Salles G, et al. Tumor necrosis factor alpha release is a major biological event associated with rituximab treatment. Hematol J 2001;2:378-384.

4. Kanelli S, Ansell SM, Habermann TM, Inwards DJ, Tuinstra N, Witzig TE. Rituximab toxicity in patients with peripheral blood malignant B-cell lymphocytosis. Leuk Lymphoma 2001;42:13291337.

5. Hainsworth JD, Litchy S, Lamb MR, Rodriguez GI, Scroggin C Jr, Greco FA. First-line treatment with brief-duration chemotherapy plus rituximab in elderly patients with intermediate-grade nonHodgkin's lymphoma: phase II trial. Clin Lymphoma 2003;4:3642.

6. Byrd JC, Peterson BL, Morrison VA, et al. Randomized phase 2 study of fludarabine with concurrent versus sequential treatment with rituximab in symptomatic, untreated patients with B-cell chronic lymphocytic leukemia: results from Cancer and Leukemia Group B 9712 (CALGB 9712). Blood 2003;101:6-14.

7. McLaughlin P, Grillo-Lopez AJ, Link BK, et al. Rituximab chimeric anti-CD2O monoclonal antibody therapy for relapsed indolent lymphoma: half of patients respond to a four-dose treatment program. J Clin Oncol 1998;16:2825-2833.

8. Burton C, Kaczmarski R, Jan-Mohamed R. Interstitial pneumonitis related to rituximab therapy. N Engl J Med 2003; 348:2690-2691.

9. Swords R, Power D, Fay M, O’Donnell R, Murphy PT. Interstitial pneumonitis following rituximab therapy for immune thrombocytopenic purpura (ITP). Am J Hematol 2004;77:103104.

10. Leon RJ, Gonsalvo A, Salas R, Hidalgo NC. Rituximab-induced acute pulmonary fibrosis. Mayo Clin Proc 2004;79:949, 953.

11. Wagner SA, Mehta AC, Laber DA. Rituximab-induced interstitial lung disease. Am J Hematol 2007;82:916-919.

12. Ennishi D, Terui Y, Yokoyama M, et al. Increased incidence of interstitial pneumonia by CHOP combined with rituximab. Int $\mathrm{J}$ Hematol. 2008;87:393-397.

13. Lee Y, Kyung SY, Choi SJ, et al. Two cases of interstitial pneumonitis caused by rituximab therapy. Korean J Intern Med 2006;21:183-186.

14. Smith MR. Rituximab (monoclonal anti-CD20 antibody): mechanisms of action and resistance. Oncogene 2003;22:73597368 .

15. van der Kolk LE, Grillo-Lopez AJ, Baars JW, Hack CE, van Oers $\mathrm{MH}$. Complement activation plays a key role in the side-effects of rituximab treatment. Br J Haematol 2001;115:807-811.

16. Alho HS, Maasilta PK, Harjula AL, Hammainen P, Salminen J, Salminen US. Tumor necrosis factor-alpha in a porcine bronchial model of obliterative bronchiolitis. Transplantation 2003;76:516523.

17. Tonelli AR, Lottenberg R, Allan RW, Sriram PS. Rituximabinduced hypersensitivity pneumonitis. Respiration 2009;78:225229.

18. Czuczman MS, Fallon A, Mohr A, et al. Rituximab in combination with CHOP or fludarabine in low-grade lymphoma. Semin Oncol 2002;29(1 Suppl 2):36-40.

19. Voog E, Morschhauser F, Solal-Celigny P. Neutropenia in patients treated with rituximab. N Engl J Med 2003;348:2691-2694. 